\title{
RESEARCH
}

Open Access

\section{Clinical and laboratory features distinguishing between Deinagkistrodon acutus and Daboia siamensis envenomation}

Hung-Yuan Su ${ }^{1,2}$, Shih-Wei Huang ${ }^{3}$, Yan-Chiao Mao ${ }^{4}$, Ming-Wen Liư ${ }^{3}$, Kuo-Hsin Lee ${ }^{1,2}$, Pei-Fang Lai ${ }^{3}$ and Ming-Jen Tsai ${ }^{5^{*}}$

\begin{abstract}
Background: There are 6 species of venomous snakes in Taiwan. Two of them, Deinagkistrodon acutus (D. acutus) and Daboia siamensis (D. siamensis), can cause significant coagulopathy. However, a significant proportion of patients with snakebites cannot identify the correct snake species after envenomation, which hampers the application of antivenom. Hence, the differential diagnosis between the two snakebites by clinical presentations is important. This study aims to compare their clinical and laboratory features for the purpose of differential diagnosis between the two snakebites.
\end{abstract}

Methods: We retrospectively reviewed the medical records of patients who arrived at the emergency department due to D. acutus or D. siamensis envenomation, between 2003 and 2016, in one medical center in eastern Taiwan. Since these snakebites are rare, we also included 3 cases reported from another hospital in central Taiwan.

Results: In total, 15 patients bitten by D. acutus and 12 patients by D. siamensis were analyzed. Hemorrhagic bulla formation and the need for surgical intervention only presented for D. acutus envenomation cases (Both $53.3 \%$ vs. $0.0 \%, P=0.003)$. As to laboratory features, lower platelet counts $\left(20.0 \times 10^{3} / \mu \mathrm{L}\right.$ [interquartile range, $14-66 \times 10^{3} / \mu \mathrm{L}$ ] vs. $\left.149.0 \times 10^{3} / \mu \mathrm{L}\left[102.3-274.3 \times 10^{3} / \mu \mathrm{L}\right], P=0.001\right)$, lower D-dimer level $(1423.4 \mu \mathrm{g} / \mathrm{L}[713.4-4212.3 \mu \mathrm{g} / \mathrm{L}] \mathrm{vs} .12,500.0 \mu \mathrm{g} / \mathrm{L}$ [2351.4-200,000 $\mathrm{mg} / \mathrm{L}], P=0.008$ ), higher proportion of patients with moderate-to-severe thrombocytopenia (platelet count $\left.<100 \times 10^{3} / \mathrm{ML}\right)(80 \%$ vs. $16.7 \%$, odds ratio $(\mathrm{OR})=20.0,95 \% \mathrm{Cl}, 2.77-144.31 ; P=0.002)$, and lower proportion of patients with extremely high D-dimer (> $5000 \mathrm{ng} / \mathrm{mL})(16.7 \%$ vs. $66.7 \%$, adjusted $\mathrm{OR}=0.1(95 \% \mathrm{Cl}, 0.01-0.69 ; P=0.036)$ were found among cases of $D$. acutus envenomation compared to $D$. siamensis envenomation. The combination of hemorrhagic bulla, thrombocytopenia, and a lack of extremely high D-dimer had good discriminatory power (area under the curve $(A \cup C)=0.965 ; 95 \% \mathrm{Cl}, 0.904-1.00$ ) for distinguishing $D$. acutus from $D$. siamensis envenomation.

Conclusions: The presentation of moderate to severe thrombocytopenia (platelet count $<100 \times 10^{3} / \mu \mathrm{L}$ ) and hemorrhagic bulla formation may indicate D. acutus envenomation. However, the envenomed patient with extremely high D-dimer levels may indicate a D. siamensis envenomation. These findings may help diagnose and select the right antivenom in patients with unknown snakebites who present significant coagulopathy.

Keywords: Coagulopathy, Deinagkistrodon acutus, Daboia siamensis, Snakebite, Thrombocytopenia

\footnotetext{
* Correspondence: tshi33@gmail.com

${ }^{5}$ Department of Emergency Medicine, Ditmanson Medical Foundation

Chia-Yi Christian Hospital, No. 539, Zhongxiao Road, East District, Chiayi City

600, Taiwan

Full list of author information is available at the end of the article
}

(c) The Author(s). 2018 Open Access This article is distributed under the terms of the Creative Commons Attribution 4.0 International License (http://creativecommons.org/licenses/by/4.0/), which permits unrestricted use, distribution, and reproduction in any medium, provided you give appropriate credit to the original author(s) and the source, provide a link to the Creative Commons license, and indicate if changes were made. The Creative Commons Public Domain Dedication waiver (http://creativecommons.org/publicdomain/zero/1.0/) applies to the data made available in this article, unless otherwise stated. 


\section{Background}

Snake envenomation is a serious and important public health issue worldwide, including in Taiwan $[1,2]$. Taiwan is a natural habitat for more than 40 snake species, including 6 types of venomous snakes with clinical importance, namely: Protobothrops mucrosquamatus (Taiwan habu), Trimeresurus stejnegeri (Taiwan bamboo viper), Deinagkistrodon acutus (D. acutus), Daboia siamensis (D. siamensis), Bungarus multicinctus (banded krait), and Naja atra (Taiwan cobra) [3, 4]. Among the abovementioned venomous species, the first 4 belong to the Viperidae family, which possess hemotoxic venom that can cause varying degrees of bleeding tendency in humans. In general, most patients with Taiwan habu or Taiwan bamboo viper envenomation present with local hemotoxic effects; however, the manifestation of systemic coagulopathy is rare and mild [5]. A previous study by Chen et al. had reported only $6 \%$ of Taiwan habu and $0 \%$ of Taiwan bamboo viper envenomation presenting coagulopathy and less than $1 \%$ of Taiwan habu presenting severe coagulopathy [6]. However, in $D$. acutus and D. siamensis envenomation, systemic coagulopathies including thrombocytopenia, prolonged prothrombin time (PT), activated partial thromboplastin time (APTT), fibrinogen consumption and D-dimer production are common [7-9].

D. acutus, also called the hundred pacer, is the largest snake of the crotalinae subfamily in Taiwan [4]. This species can inject a large amount of venom at each envenomation, with the venom containing several hemotoxins including pro-coagulation proteins, such as thrombin-like enzyme (TLE), as well as anticoagulation proteins, such as factor IX/X inhibitor and platelet aggregation inhibitor [10-13]. D. siamensis, which belongs to the viperinae subfamily, has venom composed of mixed hemotoxins, including pro-coagulation proteins, such as factor V, IX, and $\mathrm{X}$ activator, protease inhibitors, and phospholipase A2 [13-15]. The main habitats of D. acutus and D. siamensis are very similar and both are distributed from the eastern to southern regions of Taiwan [3]. Victims of these two snakebite types are rare and only account for $2.4 \%$ ( $D$. acutus) and $2.9 \%$ (D. siamensis) of the total venomous snakebites in eastern Taiwan [16]. In addition to Taiwan, these two snakes are also concurrently distributed in other Southeastern Asian countries, such as Laos and Vietnam and southern China [17].

Currently, the definitive treatment for these types of snakebites is horse-derived antivenom, specific for $D$. acutus and D. siamensis. However, previous studies have shown that about $30 \%$ of patients with venomous snakebites were unable to identify the correct snake species $[3,6]$. This leads to difficulty in administering the correct antivenom, especially in those patients with significant coagulopathy. Although the concurrent use of two specific antivenoms may be practiced clinically, the high cost in generating antivenom, low inventory, and its side effects, such as serum sickness, should also be considered [18-21]. The correct clinical differential diagnosis between these two types of snakebites is paramount.

Unlike four other types of venomous snakebites were well investigated in Taiwan, there is still a lack of data to distinguish clinical features between $D$. acutus and $D$. siamensis envenomation. The aim of this study was to investigate the clinical and laboratory differences between $D$. acutus and $D$. siamensis envenomation, which can help emergency physicians make correct clinical diagnosis, especially in those patients with systemic coagulopathy but unknown snake envenomation.

\section{Methods}

\section{Study population}

We conducted a retrospective study of patient data on $D$. acutus and D. siamensis envenomation, who were admitted to the Hualien Tzu Chi Medical Center, the only medical center in eastern Taiwan, between 2003 and 2016. The patient data collection methodology was previously described $[5,16]$. Briefly, patient medical records were collected for those admitted with snakebites, using the computerized chart system and International Classification of Diseases, 9th Revision, Clinical Modification codes 989.5, E905.0, E905.9, E906.2, and E906.5. For D. acutus and D. siamensis envenomation, classification of the snake species was based on patient identification from a photograph taken by cell phone, or bringing the snake to the emergency department (ED). We only included patients with venomous snakebites who received specific antivenoms for $D$. acutus or D. siamensis and excluded those without receiving antivenom for suspicion of dry bite. Patients who could not confirm the correct snake species and who received more than one type of antivenom were also excluded. Three authors independently reviewed the clinical records of the included patients to confirm that each patient had a relevant history, typical manifestation, and consistent antivenom administration.

Due to the rare incidence of $D$. acutus and D. siamensis envenomation, we also searched case reports of $D$. acutus or D. siamensis envenomation in Taiwan registered during the most recent 10 years in the literature. However, only Cheng et al. had published 3 cases of $D$. acutus envenomation from Taichung Veterans General Hospital in 2017 [7]. After contacting the author, we obtained the de-identifiable patients' original data and included the 3 patients in the study.

\section{Demographic data and definition of variables}

Patients' age, gender, site of snakebite, comorbidities, envenomation details, clinical presentation, laboratory results, treatment, initial antivenom therapy timing, and 
total antivenom dose were analyzed. The laboratory analysis included initial patient data obtained upon arriving at the ED, including hematology, biochemistry, and coagulation profiles. We defined leukocytosis as a white blood cell count $(\mathrm{WBC})$ of $>11.0 \times 10^{3} / \mu \mathrm{L}$; moderate-to-severe thrombocytopenia as a platelet count of $<100 \times 10^{3} / \mu \mathrm{L}$ [22]; non-coagulation in prothrombin time (PT) and activated partial thromboplastin time (aPTT) as either PT or aPTT beyond laboratory upper limits; fibrinogen consumption as fibrinogen levels of $<1.0 \mathrm{~g} / \mathrm{L}$; extremely high D-dimer levels $>5000 \mathrm{ng} / \mathrm{mL}$ [23]; acute renal impairment as creatinine levels $>1.4 \mathrm{mg} / \mathrm{dL}$ [8]; and venom-induced consumption coagulopathy as a disseminated intravascular coagulation (DIC) score $\geq 5$ points $[24,25]$. All the reference standards had been checked for consistency during the study period. If the laboratory value was beyond the laboratory upper or lower limit, it was recorded as the upper or lower limit, respectively. If the patient's initial laboratory tests were not performed in the ED, this was recorded as a missing value in the database. All patient records and information were de-identified and anonymized before the analysis. The institutional review board of the Hualien Tzu Chi Medical Center approved the study protocol (IRB106-128-B).

\section{Statistical analyses}

The normality of the quantitative variables' distribution was tested by the Kolmogorov-Smirnov test $(P>0.10)$. Comparison of continuous variables between the two types of snakebites was conducted using the Mann-Whitney U-test or Student's $t$ test, depending on variable distribution. The chi-square test or Fisher's exact test was applied for categorical variables as appropriate. Normally distributed data are expressed as mean \pm standard deviation (SD), while non-parametric data were expressed as the median [25th-75th interquartile range]. All statistical tests were two-tailed while a $P$ value of $<0.05$ was considered statistically significant. Odds ratios (ORs) were calculated using logistic regression analysis. In addition, receiver operating characteristic (ROC) curves for different combination of the significant variables were calculated to determine which clinical manifestations can distinguish these two types of snakebite. All data were analyzed through the software SPSS, version 12.0 (IBM Corp.; Armonk, NY, USA).

\section{Results}

Respective totals of 15 and 12 patients with $D$. acutus and $D$. siamensis envenomation were analyzed. Among them, 2 patients of each envenomation type identified the species by bringing the snake to the ED; the remaining patients identified the species by a photograph taken on a cell phone or by examining the standard pictures of Taiwanese venomous snakes provided by the Centers for Disease Control, R.O.C. (Taiwan).

\section{Demographic, clinical, and laboratory features}

Comparisons of patient demographic, clinical, and laboratory characteristics are listed in Tables 1 and 2. As to clinical features, there was no significant difference between the two types of snakebite in age, gender, bite location or elapsed time until hospital arrival (Table 1). Eight of 15 patients (53.3\%) with D. acutus envenomation received surgical intervention (debridement, fasciotomy, or skin graft) due to suspicion of compartment syndrome by clinical symptoms (4 patients), or tissue infection or necrosis according to local findings (4 patients), but no $D$. siamensis envenomation patient underwent surgery $(P=0.003$; Table 1$)$. Among the 8 surgical patients with $D$. acutus envenomation, mixed types of bacteria were detected in the surgical wounds of 5 patients (62.5\%). Morganella morganii and enterococcus faecalis were the leading isolated pathogens (Table 3). In relation to local signs, hemorrhagic bulla formation was presented by more than half of the $D$. acutus envenomation patients, but by none of those with $D$. siamensis envenomation ( $53.3 \%$ vs. $0.0 \%, \mathrm{P}=0.003$; Table 1 ).

As to laboratory findings, both $D$. acutus and $D$. siamensis envenomation showed a certain degree of coagulopathy including thrombocytopenia, PT and aPTT prolongation, fibrinogen consumption, and elevated D-dimer levels (Table 1). However, significantly lower platelet $(P=0.001)$ and $\mathrm{D}$-dimer levels $(P=0.008)$, but higher PT $(P=0.025)$ and DIC scores $(P=0.036)$ were found in patients with $D$. acutus envenomation (Table 1). A significantly higher proportion of patients with $D$. acutus envenomation presented with moderate-to-severe thrombocytopenia $(P=0.002 ; \mathrm{OR}=20.0,95 \%$ confidence interval [CI], 2.77-144.31) compared to patients with $D$. siamensis envenomation. However, a significantly lower proportion of patients with $D$. acutus envenomation presented with extremely high D-dimer levels compared to patients with $D$. siamensis envenomation $(\mathrm{P}=0.036$; $\mathrm{OR}$ $=0.1,95 \%$ CI, 0.01-0.69) (Table 2). The two groups did not differ significantly in WBCs, hemoglobin, fibrinogen, liver or renal function tests, or in creatine kinase levels (Tables 1 and 2).

\section{Features distinguishing between Deinagkistrodon acutus and Daboia siamensis envenomation}

We next measured and compared the discriminatory power of different combinations of clinical and laboratory features in distinguishing between $D$. acutus and $D$. siamensis envenomation by analyzing ROC curves (Fig. 1). The results showed that the combination of thrombocytopenia, hemorrhagic bulla formation, and D-dimer levels $\leq 5000 \mathrm{ng} / \mathrm{mL}$ had the best discriminatory power. The AUC of this combined model was significantly higher than thrombocytopenia-alone $(\mathrm{AUC}=$ 0.965 [95\% CI, $0.904-1.00]$ vs. 0.792 [95\% CI, 0.623- 
Table 1 Comparison of clinical and laboratory characteristics between patients with Deinagkistrodon acutus and Daboia siamensis envenomation

\begin{tabular}{|c|c|c|c|}
\hline & Deinagkistrodon acutus $(n=15)$ & Daboia siamensis $(n=12)$ & $P$ value \\
\hline Age & $47.7 \pm 13.81$ & $55.0 \pm 10.06$ & 0.140 \\
\hline Male gender & $14(93.3)$ & $9(75.0)$ & 0.294 \\
\hline \multicolumn{4}{|l|}{ Season } \\
\hline Summer \& fall & $14(93.3)$ & $6(50.0)$ & \multirow[t]{2}{*}{0.024} \\
\hline Winter and spring & $1(6.7)$ & $6(50.0)$ & \\
\hline \multicolumn{4}{|l|}{ Bite area } \\
\hline Upper limbs & $10(66.7)$ & $10(83.3)$ & \multirow[t]{2}{*}{0.408} \\
\hline Lower limbs & $5(33.3)$ & $2(16.7)$ & \\
\hline Operation & $8(53.3)$ & $0(0)$ & 0.003 \\
\hline \multicolumn{4}{|l|}{ Local signs } \\
\hline Swelling & $15(100)$ & $12(100)$ & 1.000 \\
\hline Ecchymosis & $9(60)$ & $4(33.3)$ & 0.252 \\
\hline Hemorrhagic bulla & $8(53.3)$ & $0(0)$ & 0.003 \\
\hline Time to arrive hospital (hr) & $2.0(1-7.5)$ & $7.5(1-12)$ & 0.373 \\
\hline Total dose of antivenom (vial) & $6.0(4-10)$ & $4.0(4-6)$ & 0.067 \\
\hline Duration of hospitalization (day) & $5.0(2-27)$ & $3.0(2-7)$ & 0.183 \\
\hline \multicolumn{4}{|l|}{ ED laboratory data: } \\
\hline $\mathrm{WBC}\left(\times 10^{3} / \mu \mathrm{L}\right)$ & $10.3 \pm 2.98$ & $12.1 \pm 3.90$ & 0.187 \\
\hline $\mathrm{Hb}(\mathrm{g} / \mathrm{dL})$ & $14.1 \pm 2.77$ & $14.0 \pm 1.39$ & 0.889 \\
\hline $\operatorname{PLT}\left(\times 10^{3} / \mu \mathrm{L}\right)$ & $20.0(14-66)$ & $149.0(102.3-274.3)$ & 0.001 \\
\hline PT (sec) & $100.0(100-100)$ & $75.0(11-100)$ & 0.025 \\
\hline aPTT (sec) & $150.0(25-191)(n=14)$ & $29.0(25-160)$ & 0.118 \\
\hline Fibrinogen (g/L) & $0.5(0.25-0.93)(n=13)$ & $0.5(0.25-0.95)$ & 0.689 \\
\hline D-dimer $(\mu \mathrm{g} / \mathrm{L})$ & $1423.4(713.4-4212.3)(n=12)$ & $12,500.0(2351.4-200,000.0)$ & 0.008 \\
\hline DIC score & $7.0(5-7)$ & $5.5(4-6)$ & 0.041 \\
\hline AST (IU/L) & $29.0(22-35)$ & $36.0(24-101)(n=11)$ & 0.330 \\
\hline $\mathrm{ALT}(\mathrm{IU} / \mathrm{L})$ & $22.0(18.0-44.5)(n=13)$ & $25.0(20-38)$ & 0.852 \\
\hline $\mathrm{BUN}(\mathrm{mg} / \mathrm{dL})$ & $14.0(10.8-19.5)(n=14)$ & $17.0(12.5-30.8)$ & 0.193 \\
\hline CRE (mg/dL) & $0.9(0.78-1.33)(n=14)$ & $1.2(0.93-2.38)$ & 0.118 \\
\hline CK (IU/L) & $242.0(213.5-748.0)(n=13)$ & $487.0(257-1444.5)(n=9)$ & 0.186 \\
\hline
\end{tabular}

Values shown are $\mathrm{n}(\%)$ or mean $\pm \mathrm{SD}$ or median (interquartile range)

$A L T$ alanine aminotransferase, $a P T T$ activated partial thromboplastin time, $A S T$ aspartate aminotransferase, $B U N$ blood urea nitrogen, $C K$ creatine kinase, $C R E$ creatinine. DIC disseminated intravascular coagulation, $\mathrm{Hb}$ hemoglobin, PLT platelet count, PT prothrombin time, WBC white blood cell count

0.961], $P=0.017)$. Moreover, the presentation of both thrombocytopenia and hemorrhagic bulla was also a more apt predictor for $D$. acutus envenomation (AUC = 0.924 [95\% CI, 0.820-1.00]; $P=0.06$, when compared to thrombocytopenia-alone; $P=0.097$, when compared to the combined model of thrombocytopenia, hemorrhagic bulla and low D-dimer levels) (Fig. 1).

\section{Discussion}

In this retrospective study, we discovered that the presentation of hemorrhagic bulla formation and the type of surgical intervention are clinical features indicating D. acutus envenomation. The laboratory findings of moderate-to-severe thrombocytopenia may indicate $D$. acutus envenomation while cases of patients with extremely high D-dimer levels most likely resulted from D. siamensis envenomation. Combining the clinical manifestations of thrombocytopenia, hemorrhagic bulla formation and D-dimer levels can help us to distinguish between these two snakebite types.

Different from the other two venomous snakes of the Viperidae family, Taiwan habu and Taiwan bamboo viper, severe systemic coagulopathy with a DIC score $\geqq 5$ can be found in most instances of D. acutus (86.7\%) and D. siamensis (58.3\%) envenomation (Table 2). This proportion is far higher than that of the Taiwan habu $(<1 \%)$ 
Table 2 Laboratory characteristics of patients with Deinagkistrodon acutus and Daboia siamensis envenomation

\begin{tabular}{|c|c|c|c|c|}
\hline & \multirow{2}{*}{$\begin{array}{l}\text { Deinagkistrodon acutus }(\mathrm{n}=15) \\
\mathrm{n}(\%)\end{array}$} & \multirow{2}{*}{$\begin{array}{l}\text { Daboia siamensis }(\mathrm{n}=12) \\
\mathrm{n}(\%)\end{array}$} & \multirow[t]{2}{*}{$P$ value } & \multirow[t]{2}{*}{ OR $(95 \% \mathrm{Cl})$} \\
\hline & & & & \\
\hline 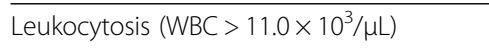 & $8(53.3)$ & $8(66.7)$ & 0.696 & $0.57(0.12-2.75)$ \\
\hline $\begin{array}{l}\text { Moderate-to-severe thrombocytopenia } \\
\left(\mathrm{PLT}<100 \times 10^{3} / \mu \mathrm{L}\right)\end{array}$ & $12(80.0)$ & $2(16.7)$ & 0.002 & $20.00(2.77-144.31)$ \\
\hline Noncoagulation in aPTT & $11(73.3)$ & $4(33.3)$ & 0.057 & $5.50(1.05-28.88)$ \\
\hline Noncoagulation in PT & $13(86.7)$ & $7(58.3)$ & 0.185 & $4.64(0.71-30.42)$ \\
\hline Fibrinogen consumption (< $1 \mathrm{~g} / \mathrm{L})$ & $10(76.9)$ & $9(75.0)$ & 1.000 & $1.11(0.18-6.97)$ \\
\hline Extremely high D-dimer (> 5000 ng/mL) & $2(16.7)$ & $8(66.7)$ & 0.036 & $0.10(0.01-0.69)$ \\
\hline DIC score $\geqq 5$ & $13(86.7)$ & $7(58.3)$ & 0.185 & $4.64(0.71-30.42)$ \\
\hline Acute renal impairment (CRE $>1.4 \mathrm{mg} / \mathrm{dL}$ ) & $3(20.0)$ & $5(41.7)$ & 0.398 & $0.35(0.06-1.93)$ \\
\hline
\end{tabular}

Values shown are $\mathrm{n}(\%)$. N/A not applicable

aPTT activated partial thromboplastin time, $A S T$ aspartate aminotransferase, $B U N$ blood urea nitrogen, $C l$ confidence interval, $C K$ creatine kinase, $C R E$ creatinine, DIC disseminated intravascular coagulation, OR odds ratio, PLT platelet count, $P T$ prothrombin time, WBC white blood cell count

and Taiwan bamboo viper (0\%) envenomation in previous observation [6]. Moreover, noncoagulation in PT and aPTT, and severe fibrinogen consumption was also found in a significant proportion of patients with D. acutus and D. siamensis envenomation (Table 2). These findings were also uncommon in Taiwan habu or Taiwan bamboo viper envenomation $[5,6]$. Thus, the above manifestation of coagulopathy may be a suitable indicator to discriminate $D$. acutus and $D$. siamensis from Taiwan habu and Taiwan bamboo viper envenomation.

Among the significant differences in clinical manifestation between $D$. acutus and $D$. siamensis envenomation found in our study are abnormalities in the coagulation profiles. Both $D$. acutus and $D$. siamensis venoms are composed of several hemotoxins with varying degrees of procoagulant and anticoagulant effects, which act on different steps of the clotting pathway and consume different clotting factors.

D. acutus venom clinically presents as anticoagulant toxins, platelet aggregation inhibitors, hemorrhagins,

Table 3 Bacterial isolates identified from snakebite wounds of patients with Deinagkistrodon acutus envenomation who underwent surgery

\begin{tabular}{ll}
\hline Pathogen & $n$ \\
\hline Aerobic gram-positive bacteria & 3 \\
Enterococcus faecalis & 2 \\
Staphylococcus aureus & 3 \\
Aerobic gram-negative bacteria & 2 \\
Morganella morganii & 1 \\
Pseudomonas aeruginosa & \\
Citrobacter freundii & 2 \\
Anaerobic bacteria &
\end{tabular}

More than one type of bacteria were isolated from snakebite wound in 3 patients who underwent surgery due to Deinagkistrodon acutus envenomation and TLEs $[10,12,26,27]$. The anticoagulant toxins of $D$. acutus directly inhibit coagulation factors V and IX/X, prothrombin and tissue factors, resulting in immediate and marked prolongation of the coagulation time after envenomation [10, 28, 29]. TLEs can break down fibrinogen, but unlike real thrombin, which can activate factor XIII to perform fibrin cross-linking and stabilize fibrin clots, TLE does not form fibrin clots and produce fibrin degradation products (D-dimer) [30-33]. However, in $D$. siamensis venom the main components are phospholipase A2 and pro-coagulation proteins, which include factor $\mathrm{V}$, IX, and $\mathrm{X}$ activators, and are very potent $[14,15,30-32,34]$. The activators can persistently activate the coagulation pathway, and, finally, consume massive downstream coagulation factors, resulting in clotting factor deficiency, hypofibrinogenemia, fibrinolysis, and greatly elevated D-dimer levels $[8,35]$. Because the main etiology leading to coagulopathy in $D$. siamensis envenomation is consumptive coagulopathy, the prolongation of coagulation time is time-dependent; severe prolongation of PT and aPTT may occur subsequently after consuming the clotting factors. The abovementioned mechanism may explain the extremely high D-dimer levels in our $D$. siamensis envenomation patients, but relatively lower D-dimer levels in $D$. acutus envenomation, as well as the finding that more $D$. acutus envenomation patients presented with non-coagulation in PT and aPTT.

Another difference found between $D$. acutus and $D$. siamensis envenomation is local wound complication. More than half of $D$. acutus envenomation patients developed extensive hemorrhagic bulla formations, requiring surgical intervention due to suspected compartment syndrome or tissue infection and necrosis. However, none of the $D$. siamensis envenomation patients presented any significant local tissue injury and none required surgical intervention. We further found that $D$. 


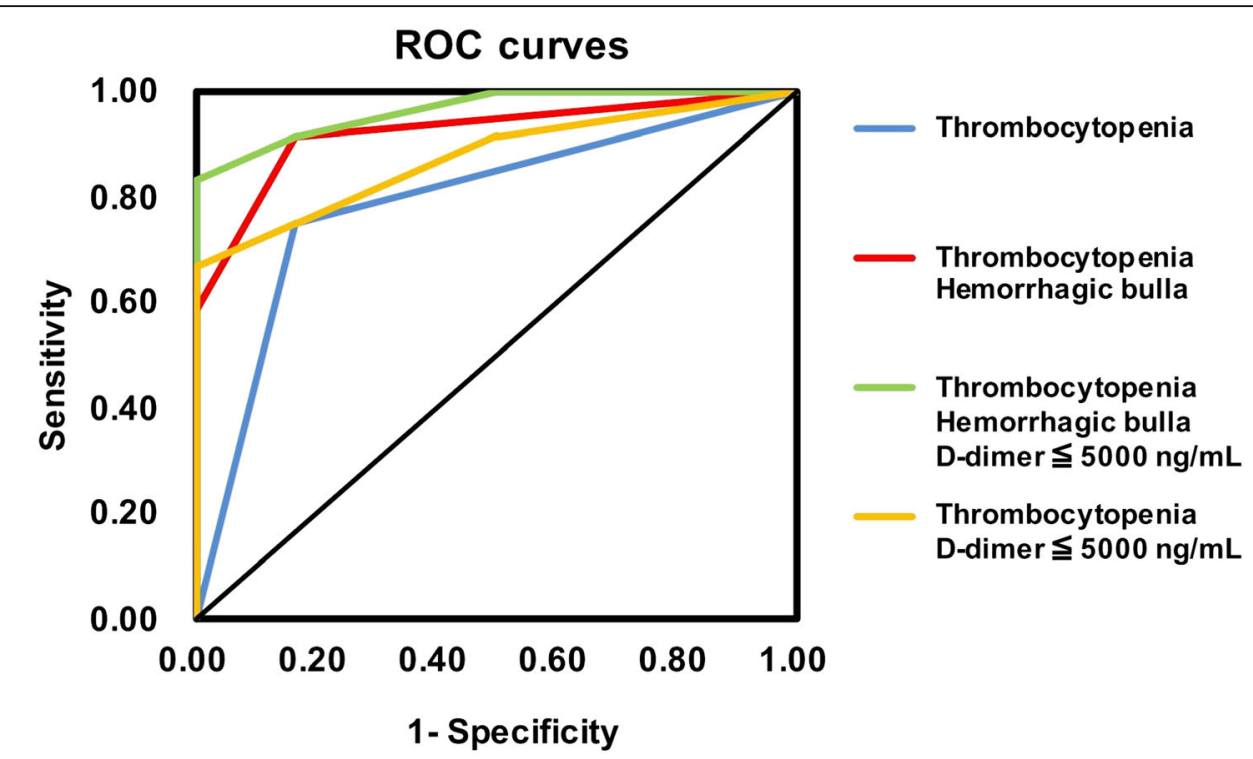

\begin{tabular}{lccc} 
Clinical manifestations & AUC $(95 \% \mathrm{Cl})$ & \multicolumn{2}{c}{ P Value } \\
\hline Thrombocytopenia & $0.792(0.623,0.961)$ & Reference & \\
$\begin{array}{l}\text { Thrombocytopenia } \\
\text { Hemorrhagic bulla }\end{array}$ & $0.924(0.820,1.000)$ & 0.060 & Reference \\
$\begin{array}{l}\text { Thrombocytopenia } \\
\begin{array}{l}\text { Hemorrhagic bulla } \\
\text { D-dimer } \leqq 5000 \mathrm{ng} / \mathrm{mL}\end{array}\end{array}$ & $0.965(0.904,1.000)$ & 0.017 & 0.097 \\
$\begin{array}{l}\text { Thrombocytopenia } \\
\text { D-dimer } \leqq 5000 \mathrm{ng} / \mathrm{mL}\end{array}$ & $0.875(0.731,1.000)$ & & \\
\hline
\end{tabular}

Fig. 1 Receiver-operating characteristic (ROC) curves for the different combinations of clinical manifestations in distinguishing $D$. acutus envenomation from D. siamensis envenomation. Thrombocytopenia means platelet count $<100 \times 10^{3} / \mathrm{uL}$

acutus envenomation patients who had undergone surgery showed evidence of wound infection. The isolated bacteria from the surgical wounds are usually a mixed spectrum, including aerobic Gram-positive and -negative, and anaerobic bacteria. This finding indicates that wound infection may partly contribute to complication in cases of $D$. acutus envenomations. The use of broad-spectrum antibiotics to cover mixed bacterial infection may be necessary in $D$. acutus envenomation. In addition, being the most venomous snake of the crotalinae subfamily in Taiwan, $D$. acutus can inject 3,5 , and 15 times the amount of venom per envenomation than that of Protobothrops mucrosquamatus, D. siamensis and Trimeresurus stejnegeri, respectively [13]. Local hemotoxic venom can affect coagulation, destroy endothelial cells and tissue, increase vascular permeability, and cause extensive vascular damage, which may explain the extensive wound complications observed in D. acutus envenomations [36]. Conversely, the venom amount in each injection of $D$. siamensis bite was much less than that of D. acutus [13]. Although, similar toxic proteins exist in the venom of $D$. siamensis, relatively weaker local tissue effects were associated with $D$. siamensis envenomation in this study; similar findings in relation to D. siamensis in Taiwan have been reported $[8,9]$.

In our study, moderate-to-severe thrombocytopenia was the most significant feature that could discriminate between $D$. acutus and D. siamensis envenomation. Both envenomations are likely to develop thrombocytopenia, but $D$. acutus causes more severe thrombocytopenia. Previous studies have demonstrated that $D$. acutus venom contains components that target platelets [25, 37-40]. However, the mechanism of severe thrombocytopenia in $D$. acutus envenomation has scarcely been investigated in in vitro. Nonetheless, previous studies in rat models and humans both demonstrate this result $[7,15]$. In human cases of $D$. acutus envenomation, severe thrombocytopenia was found in patients within $4 \mathrm{~h}$ after a snakebite [7]. In rat 
experiments, severe thrombocytopenia was found within 10 min after injecting agkicetin-C, a potent antagonist of platelet glycoprotein Ib-IX-V, purified from $D$. acutus venom [39]. In addition to the possible direct venom effects that result in platelet consumption, sequestration of platelets by extensive tissue and vascular injury, and the severe wound infections found in $D$. acutus envenomation may all contribute to severe thrombocytopenia in humans with $D$. acutus envenomation.

However, thrombocytopenia in D. siamensis is thought to be related to thrombin-induced platelet aggregation and activation [34]. The pro-coagulation proteins found in $D$. siamensis venom produce massive fibrin clots and consume platelets to form systemic microthrombi [9, 41]. Although severe thrombocytopenia may also occur in D. siamensis envenomation, it usually takes more than $12 \mathrm{~h}$ after the snakebite for thrombocytopenia to occur in these patients [8].

In order to apply our findings to the clinical practice of EDs, we focused our analysis on simply defined abnormalities of coagulation profiles, such as extremely high D-dimer levels and noncoagulation in PT or aPTT, but we did not measure the optimal cutoff point via the ROC curve from individual laboratory data. Moreover, when considering that a single clinical feature may not be acceptable to accurately differentiate between these two types of snakebites, we combined different clinical and laboratory features to optimize the ROC curve. The combined model using thrombocytopenia, hemorrhagic bulla formation, and a lack of extremely high D-dimer levels had the best discriminatory power in distinguishing $D$. acutus from $D$. siamensis envenomation $(\mathrm{AUC}=$ 0.965 [95\% CI, 0.904-1.000]). Combining the two features of thrombocytopenia and hemorrhagic bulla formation is also an acceptable diagnostic marker in distinguishing these two types of snakebites (AUC $=0.924$ [95\% CI, 0.820-1.000]).

There are several limitations in our study. First, this is a 13-year retrospective study and all patient data were collected from patient charts or electronic medical records. Non-uniform descriptions of signs or symptoms recorded by different physicians may influence and induce some bias. Second, although this is the largest native study regarding $D$. acutus and $D$. siamensis envenomation over the last 20 years in Taiwan, the sample size was still small due to the rarity of both types of snakebites. Third, due to the lack of a definitive guideline to manage these two snakebites in Taiwan, different treatment strategies in clinical practice might influence clinical outcomes and result in the missing values of some laboratory tests. Fourth, although we tried our best to discriminate snake species according to patient's identification, clinical symptoms or defined criteria, there is still probable misidentification owing to non-visible real snake in ED. A prospective study conducted to validate our findings should be considered. In addition, the time-dependent change in coagulation profiles, the quantification of specific clotting factors, such as factor $\mathrm{X}$, and development of the severity grading system should be considered in further studies.

\section{Conclusions}

Among the 6 most common venomous snakes in Taiwan, life-threatening coagulopathy is frequently attributed to either D. acutus or D. siamensis envenomation. In the clinical differential diagnosis between these two types of snakebites, the presence of hemorrhagic bulla and moderate-to-severe thrombocytopenia are clinical features uniquely associated with $D$. acutus envenomation. However, extremely high D-dimer levels are indicative of $D$. siamensis envenomation.

\section{Abbreviations \\ APTT: Activated partial thromboplastin time; AUC: Area under curve; D. acutus: Deinagkistrodon acutus; D. siamensis: Daboia siamensis; DIC: Disseminated intravascular coagulation; ED: Emergency department; ORs: Odds ratios; PT: Prothrombin time (PT); ROC: Receiver operating characteristic; TLE: Thrombin-like enzyme; WBC: White blood cell count}

\section{Acknowledgements}

We thank Miss Wan-Ting Huang and the Department of Medical Research of Ditmanson Medical Foundation, Chia-Yi Christian Hospital for assistance with the statistical analysis.

\section{Funding}

Not applicable.

\section{Availability of data and materials}

The datasets used and/or analyzed during the current study are available from the corresponding author upon reasonable request.

\section{Authors' contributions}

The first two authors, HUS and SWH interpreted the clinical findings and drafted the manuscript. The third authors, YCM provide detailed data collection from Taichung Veteran General Hospital and provided professional opinion. The fourth and sixth authors, MWL and PFL provided data collection from Hualien Tzu Chi Medical center and professional opinion. The fifth author KHL provide professional opinion and help revised the manuscript. The correspondent author MJT designed this study, interpreted the clinical findings and revised the manuscript. All authors read and approved the final manuscript.

\section{Ethics approval and consent to participate \\ The institutional review board of the Hualien Tzu Chi Medical Center approved the study protocol (IRB106-128-B).}

\section{Consent for publication}

Not applicable.

\section{Competing interests}

The authors declare that they have no competing interests.

\section{Publisher's Note}

Springer Nature remains neutral with regard to jurisdictional claims in published maps and institutional affiliations.

\section{Author details}

${ }^{1}$ Department of Emergency Medicine, E-Da Hospital and I-Shou University, Kaohsiung, Taiwan. ${ }^{2}$ The School of Chinese Medicine for Post Baccalaureate, 
I-Shou University, Kaohsiung, Taiwan. ${ }^{3}$ Department of Emergency Medicine, Buddhist Tzu Chi General Hospital, Hualien, Taiwan. ${ }^{4}$ Division of Clinical Toxicology, Department of Emergency Medicine, Taichung Veterans General Hospital, Taichung, Taiwan. ${ }^{5}$ Department of Emergency Medicine, Ditmanson Medical Foundation Chia-Yi Christian Hospital, No. 539, Zhongxiao Road, East District, Chiayi City 600, Taiwan.

Received: 27 August 2018 Accepted: 6 December 2018

Published online: 27 December 2018

\section{References}

1. Chippaux JP, Akaffou MH, Allali BK, Dosso M, Massougbodji A, Barraviera B. The 6 (th) international conference on envenomation by snakebites and scorpion stings in Africa: a crucial step for the management of envenomation. J Venom Anim Toxins incl Trop Dis. 2016;22:11. https://doi. org/10.1186/s40409-016-0062-y.

2. Chippaux JP. Snakebite envenomation turns again into a neglected tropical disease! J Venom Anim Toxins incl Trop Dis. 2017;23:38. https://doi.org/10. 1186/s40409-017-0127-6.

3. Hung DZ. Taiwan's venomous snakebite: epidemiological, evolution and geographic differences. Trans R Soc Trop Med Hyg. 2004;98(2):96-101.

4. Mao YC, Hung DZ. Epidemiology of snake envenomation in Taiwan. In: Gopalakrishnakone P, Faiz A, Fernando R, Gnanathasan CA, Habib AG, Yang CC, editors. Clinical toxinology in Asia Pacific and Africa. Dordrecht: Springer; 2015. p. 3-22.

5. Su HY, Li YH, Tang CN, Su Cl, Tsai MJ. Can surgery in patient with Protobothrops mucrosquamatus envenomation be predicted in emergency department? Hong Kong J Emerg Med. 2016;23(4):210-9.

6. Chen YW, Chen MH, Chen YC, Hung DZ, Chen CK, Yen DH, et al. Differences in clinical profiles of patients with Protobothrops mucrosquamatus and Viridovipera stejnegeri envenoming in Taiwan. Am J Trop Med Hyg. 2009; 80(1):28-32.

7. Cheng CL, Mao YC, Liu PY, Chiang LC, Liao SC, Yang CC. Deinagkistrodon acutus envenomation: a report of three cases. J Venom Anim Toxins incl Trop Dis. 2017;23:20. https://doi.org/10.1186/s40409-017-0111-1.

8. Hung DZ, Wu ML, Deng JF, Lin-Shiau SY. Russell's viper snakebite in Taiwan: differences from other Asian countries. Toxicon. 2002;40(9):1291-8.

9. Hung DZ, Yu YJ, Hsu CL, Lin TJ. Antivenom treatment and renal dysfunction in Russell's viper snakebite in Taiwan: a case series. Trans R Soc Trop Med Hyg. 2006;100(5):489-94.

10. Ouyang C, Teng CM. In vivo effects of the purified thrombin-like and anticoagulant principles of Agkistrodon acutus (hundred pace snake) venom. Toxicon. 1978;16(6):583-93.

11. Cox AC. Coagulation factor $X$ inhibitor from hundred-pace snake (Deinagkistrodon acutus) venom. Toxicon. 1993;31(11):1445-57.

12. Xu X, Wang C, Liu J, Lu Z. Purification and characterization of hemorrhagic components from Agkistrodon acutus (hundred pace snake) venom. Toxicon. 1981;19(5):633-44.

13. Liau MY, Huang RJ. Toxoids and antivenoms of venomous snakes in Taiwan. J Toxicol. 1997;16(3):163-75.

14. Schiffman S, Theodor I, Rapaport SI. Separation from Russell's viper venom of one fraction reacting with factor $\mathrm{X}$ and another reacting with factor $\mathrm{V}$. Biochemistry. 1969;8(4):1397-405.

15. Kasturi $\mathrm{S}$, Gowda TV. Purification and characterization of a major phospholipase A2 from Russell's viper (Vipera russelli) venom. Toxicon. 1989; 27(2):229-37.

16. Su HY, Wang MJ, Li YH, Tang CN, Tsai MJ. Can surgical need in patients with Naja atra (Taiwan or Chinese cobra) envenomation be predicted in the emergency department? Hong Kong Med J. 2016;22(5):435-44.

17. McDiarmid RW, Campbell JA. Toure' TA. Snake species of the world: a taxonomic and geographical reference, vol. 1. Washington, DC: The Herpetologists' League; 1999.

18. Gold BS, Dart RC, Barish RA. Bites of venomous snakes. N Engl J Med. 2002; 347(5):347-56

19. de Silva HA, Ryan NM, de Silva HJ. Adverse reactions to snake antivenom, and their prevention and treatment. Br J Clin Pharmacol. 2015;81(3): 446-52.

20. Hamza M, Idris MA, Maiyaki MB, Lamorde M, Chippanux JP, Warrell DA, et al. Cost-effectiveness of antivenoms for snakebite envenoming in 16 countries in West Africa. PLoS Negl Trop Dis. 2016;10(3):e0004568.
21. Morais $V$. Antivenom therapy: efficacy of premedication for the prevention of adverse reactions. J Venom Anim Toxins incl Trop Dis. 2018;24:7. https:// doi.org/10.1186/s40409-018-0144-0.

22. Williamson DR, Albert M, Heels-Ansdell D, Arnold DM, Lauzier F, Zarychanski R, et al. Thrombocytopenia in critically ill patients receiving thromboprophylaxis: frequency, risk factors, and outcomes. Chest. 2013;144(4):1207-15.

23. Schutte T, Thijs A, Smulders YM. Never ignore extremely elevated D-dimer levels: they are specific for serious illness. Neth J Med. 2016;74(10):443-8.

24. Isbister GK. Snakebite doesn't cause disseminated intravascular coagulation: coagulopathy and thrombotic microangiopathy in snake envenoming. Semin Thromb Hemost. 2010;36(4):444-51.

25. Levi M, Toh CH, Thachil J, Watson HG. Guidelines for the diagnosis and management of disseminated intravascular coagulation. British Committee for Standards in Haematology. Br J Haematol. 2009;145(1):24-33.

26. Ouyang C, Huang TF. Platelet aggregation inhibitors from Agkistrodon acutus snake venom. Toxicon. 1986;24(11-12):1099-106.

27. Xu X, Wang XS, Xi XT, Liu J, Huang JT, Lu ZX. Purification and partial characterization of hyaluronidase from five pace snake (Agkistrodon acutus) venom. Toxicon. 1982;20(6):973-81.

28. Ouyang C, Teng CM. The effect of the purified anticoagulant principle of Agkistrodon acutus venom on blood coagulation. Toxicon. 1973;11(3):287-92.

29. Kini RM. Anticoagulant proteins from snake venoms: structure, function and mechanism. Biochem J. 2006;397(Pt 3):377-87.

30. Markland FS. Snake venoms and the hemostatic system. Toxicon. 1998; 36(12):1749-800.

31. Isbister GK. Procoagulant snake toxins: laboratory studies, diagnosis, and understanding snakebite coagulopathy. Semin Thromb Hemost. 2009;35(1): 93-103.

32. Maduwage K, Isbister GK. Current treatment for venom-induced consumption coagulopathy resulting from snakebite. PLoS Negl Trop Dis. 2014;8(10):e3220.

33. Sajevic T, Leonardi A, Krizaj I. Haemostatically active proteins in snake venoms. Toxicon. 2011;57(5):627-45.

34. Than T, Hutton RA, Myint-Lwin K-E-H, Soe-Soe T-N-S, et al. Haemostatic disturbances in patients bitten by Russell's viper (Vipera russelli siamensis) in Burma. Br J Haematol. 1988;69(4):513-20.

35. Warrell DA. Snake venoms in science and clinical medicine. 1. Russell's viper: biology, venom and treatment of bites. Trans R Soc Trop Med Hyg. 1989; 83(6):732-40.

36. Anz AW, Schweppe M, Halvorson J, Bushnell B, Sternberg M, Andrew Koman L. Management of venomous snakebite injury to the extremities. J Am Acad Orthop Surg. 2010;18(12):749-59.

37. Chen RH, Chen YC. Isolation of an acidic phospholipase A2 from the venom of Agkistrodon acutus (five pace snake) and its effect on platelet aggregation. Toxicon. 1989;27(6):675-82.

38. Kamiguti AS. Platelets as targets of snake venom metalloproteinases. Toxicon. 2005;45(8):1041-19.

39. Xu G, Ulrichts H, Vauterin S, De Meyer SF, Deckmyn H, Teng M, et al. How does agkicetin-C bind on platelet glycoprotein Ibalpha and achieve its platelet effects? Toxicon. 2005;45(5):561-70.

40. Wang WJ. Purification and functional characterization of AAV1, a novel P-III metalloproteinase, from Formosan Agkistrodon acutus venom. Biochimie. 2007;89(1):105-15.

41. Wu RC, Chou PT, Chen LK. Aspirin plus tirofiban inhibit the thrombosis induced by Russell's viper venom. Thromb J. 2016;14(Suppl 1):38.

\section{Ready to submit your research? Choose BMC and benefit from:}

- fast, convenient online submission

- thorough peer review by experienced researchers in your field

- rapid publication on acceptance

- support for research data, including large and complex data types

- gold Open Access which fosters wider collaboration and increased citations

- maximum visibility for your research: over $100 \mathrm{M}$ website views per year

At BMC, research is always in progress.

Learn more biomedcentral.com/submissions 